\title{
Successful Treatment of Nivolumab-related Cholangitis with Prednisolone: A Case Report and Review of the Literature
}

\author{
Koji Sawada ${ }^{1}$, Tatsuya Shonaka ${ }^{2}$, Yuji Nishikawa ${ }^{3}$, Kimiharu Hasegawa ${ }^{2}$, Hidemi Hayashi ${ }^{1}$, \\ Takumu Hasebe ${ }^{1}$, Shunsuke Nakajima ${ }^{1}$, Katsuya Ikuta ${ }^{1}$, Mikihiro Fujiya ${ }^{1}$, \\ Hiroyuki Furukawa ${ }^{2}$ and Toshikatsu Okumura ${ }^{1}$
}

\begin{abstract}
:
The patient was a 76-year-old man who was treated with nivolumab due to recurrent gastric cancer. A blood examination revealed grade 3 alkaline phosphatase (ALP) elevation. A histopathological examination revealed marked portal infiltration, including eosinophils and CD4+ and CD8+ T lymphocytes, suggesting nivolumab-related cholangitis accompanied by the features of both an immune-related adverse event (irAE) and drug-induced liver injury (DILI) with allergic reaction. The patient's ALP level immediately decreased after the administration of prednisolone. Although nivolumab-related cholangitis, a rare irAE, has been reported to be refractory to steroid therapy, patients with features of irAE and allergic DILI might immediately respond to prednisolone.
\end{abstract}

Key words: nivolumab-related cholangitis, prednisolone, eosinophils, immune-related adverse event, druginduced liver injury

(Intern Med 58: 1747-1752, 2019)

(DOI: 10.2169/internalmedicine.2330-18)

\section{Introduction}

Nivolumab, a human immunoglobulin G4 monoclonal antibody, inhibits the interaction between the programmed cell death- 1 (PD-1) receptor and its ligands (PD-L1 and PD-L2) and restores antitumor immunity $(1,2)$. Based on evidence of its antitumor effects, nivolumab is approved for the treatment of various advanced malignancies, including melanoma (3), non-small cell lung cancer (NSCLC) (4), renal cell carcinoma (RCC) (5), squamous cell carcinoma of the head and neck (6), Hodgkin's lymphoma (7), and gastric cancer (8).

Given that nivolumab is an immunomodulatory agent, specific immune-related adverse events (irAEs) caused by dysregulation of the host immune system occasionally occur during treatment (9). Typical irAEs in nivolumab-treated patients with NSCLC or gastric cancer include skin rash and diarrhea, which are reported to occur in $6.0-11.0 \%$ and 7.0 $10.0 \%$ of patients, respectively $(4,8)$. The minor but important irAEs include endocrinopathies (4), pneumonitis (10), type 1 diabetes mellitus (11), and acute hepatitis $(8,12)$. Recently, nivolumab-related cholangitis has been reported as a rare irAE in patients with NSCLC and melanoma (13-17). In addition, the Ministry of Health, Labor and Welfare in Japan called for more research on nivolumab-related cholangitis, after 10 cases of cholangitis after administration of nivolumab were reported on July 5th, 2017. As previous reports suggested that nivolumab-related cholangitis is a serious irAE that shows a moderate to poor response to steroid therapy (13-17). Thus, patients could not often receive alternative chemotherapy.

We herein report a case of nivolumab-related cholangitis accompanied by features of both irAE and drug-induced liver injury (DILI) with allergic reaction in a patient with advanced gastric cancer. Interestingly, the patient showed an

${ }^{1}$ Division of Gastroenterology and Hematology/Oncology, Department of Medicine, Asahikawa Medical University, Japan, ${ }^{2}$ Division of Gastroenterological and General Surgery, Department of Surgery, Asahikawa Medical University, Japan and ${ }^{3}$ Division of Tumor Pathology, Department of Pathology, Asahikawa Medical University, Japan

Received: November 1, 2018; Accepted: December 9, 2018; Advance Publication by J-STAGE: February 25, 2019

Correspondence to Dr. Koji Sawada, k-sawada@asahikawa-med.ac.jp 

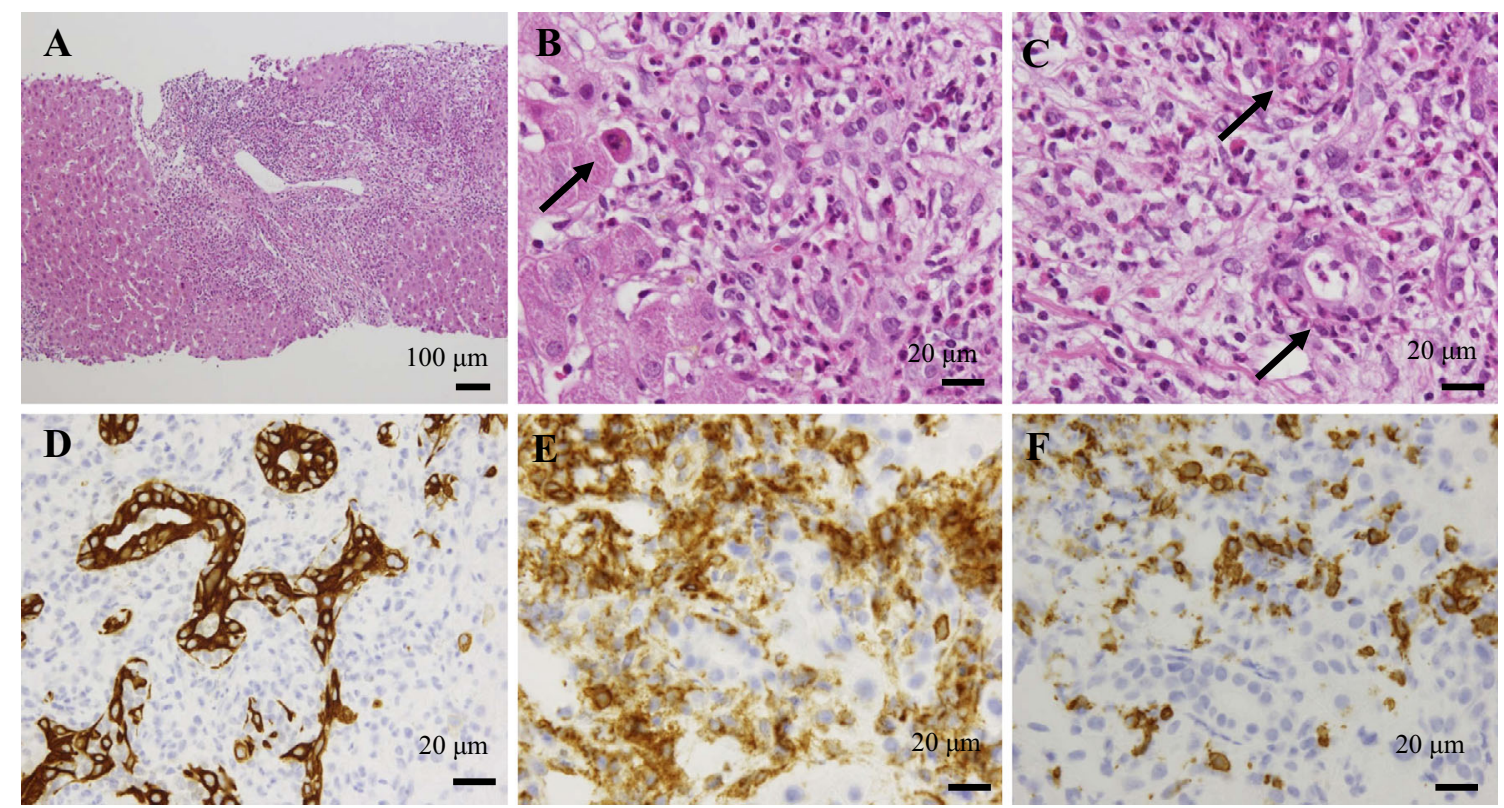

Figure 1. The histopathological examination of the biopsy specimens. A: Enlargement of the portal tract with marked inflammatory cell infiltration. B: Diffuse portal infiltration of mixed inflammatory cells with a predominance of eosinophils accompanied by mild interface hepatitis (arrow, acidophilic body). C: Infiltration of eosinophils within the epithelial linings of the intrahepatic bile ducts (arrows). D: Mild ductular reaction within the inflamed portal tract. E, F: Infiltration of both CD4+helper T-cells and CD8+suppressor T-cells in the portal tract. Hematoxylin and Eosin staining (A-C); immunohistochemical staining of CK7 (D), CD4 (E), and CD8 (F). CK: cytokeratin

immediate response to prednisolone and was able to receive alternative chemotherapy.

\section{Case Report}

The patient was a 76-year-old man who had undergone distal gastrectomy and lateral hepatectomy for advanced gastric cancer and liver metastasis, respectively, after neoadjuvant chemotherapy four years previously. A histopathological examination revealed HER2-negative well-differentiated tubular adenocarcinoma. He received adjuvant chemotherapy with S-1. However, 12 months later, abdominal lymph node metastases appeared, and he subsequently received other systemic chemotherapies. At three years after surgery, he was treated with nivolumab as the 4th-line chemotherapy. Although a physical examination showed no jaundice or abdominal symptoms, after the administration of 4 cycles of nivolumab, a blood examination revealed grade 3 alkaline phosphatase elevation (ALP: 2,427 U/L) and grade 2 gamma glutamyl transferase elevation ( $\gamma$ GTP: $252 \mathrm{U} / \mathrm{L}$ ). However, only mild elevation of the patient's aspartate aminotransferase (AST: $69 \mathrm{U} / \mathrm{L}$ ) and alanine transaminase (ALT: $68 \mathrm{U} /$ L) levels was noted (Table 1). Although computed tomography imaging revealed mild dilation of the extrahepatic bile duct, no dilation or obvious obstruction of the intrahepatic bile duct was noted. A blood examination revealed an increased eosinophil count $(6.4 \%)$, no viral hepatitis infection ( $\mathrm{HAV}, \mathrm{HBV}, \mathrm{HCV}$, and $\mathrm{HEV}$ ), and indications of previous cytomegalovirus (CMV) and Epstein-Barr virus (EBV) in- fection. The patient's serum immunoglobulin $\mathrm{G}(\mathrm{IgG}), \mathrm{IgG} 4$, and $\operatorname{IgM}$ levels were normal. The patient was negative for anti-nuclear antibody, anti-mitochondrial antibody (AMA), AMA-M2, and anti-smooth muscle antibody (Table 1). Because these blood abnormalities were not typical for hepatic irAE, the patient was treated with ursodeoxycholic acid (UDCA) as a liver support therapy, after which his serum AST and ALT levels decreased. However, his serum ALP and $\gamma$ GTP levels did not improve; thus, liver biopsy was performed. A histopathological examination of the liver biopsy specimens revealed marked portal infiltration of mixed inflammatory cells, including eosinophils (Fig. 1A and B), which was accompanied by mild interface hepatitis with the appearance of a few acidophilic bodies (Fig. 1B). Eosinophils had infiltrated the epithelial lining of the interlobular bile ducts (Fig. 1C), and cytokeratin 7 immunohistochemistry revealed a mild ductular reaction (Fig. 1D). Most infiltrating lymphocytes were CD3+ (data not shown), and included both CD4+ helper $\mathrm{T}$ cells and $\mathrm{CD} 8+$ suppressor $\mathrm{T}$ cells (Fig. 1E and F).

Because the histopathological findings indicated portal infiltration of mixed inflammatory cells and atypical acute hepatitis as an irAE, we initially suspected cholangitis due to biliary tract infection; thus, antibiotic treatment was initiated. However, the serum ALP and $\gamma$ GTP levels did not improve. Thus, the patient was diagnosed with nivolumabrelated cholangitis with an irAE based on the histopathological findings of CD4+ and CD8+ T lymphocyte infiltration in the portal tract. In addition, the portal infiltration of eosino- 


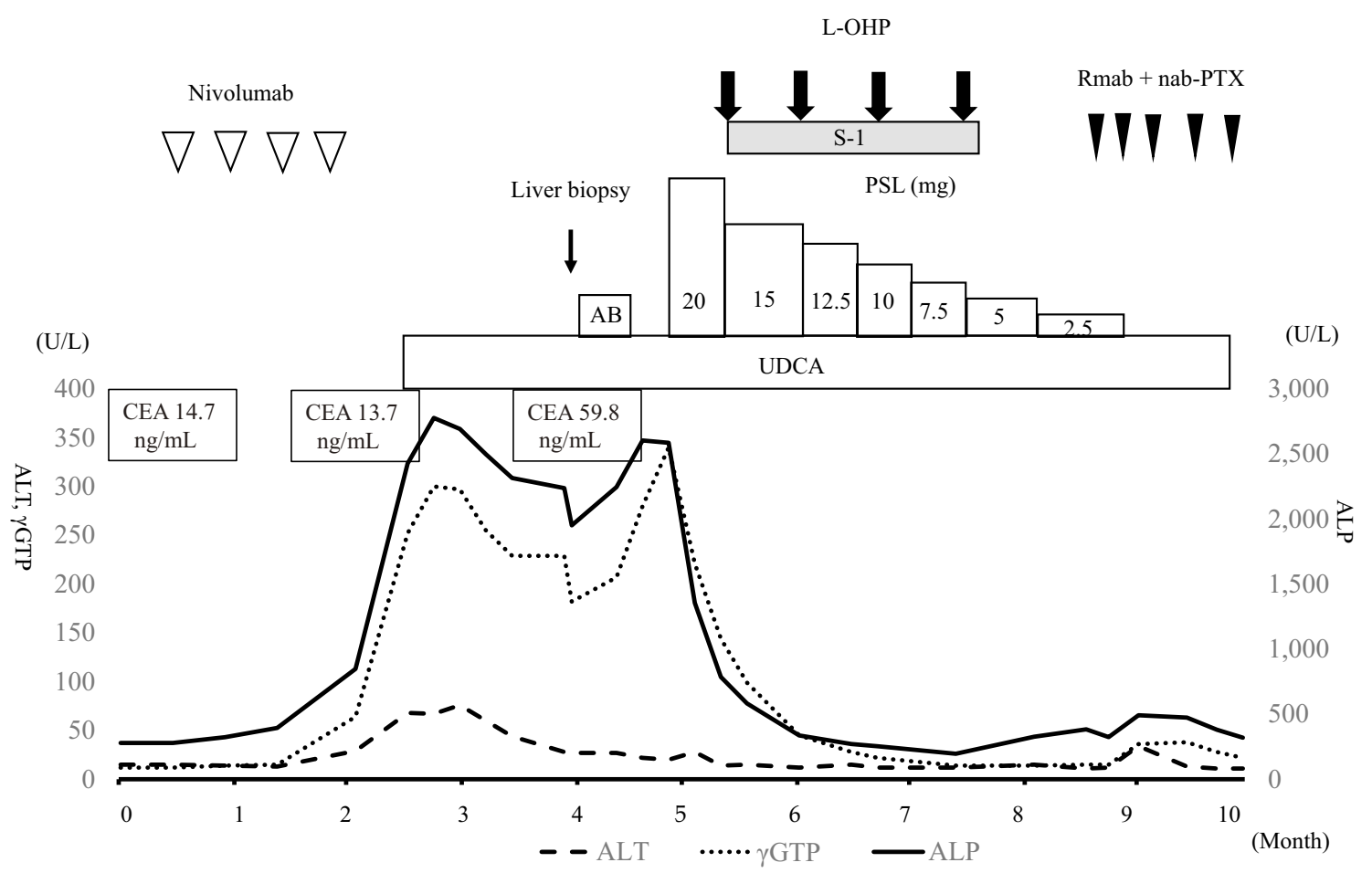

Figure 2. Clinical course. The patient's biliary enzyme levels were increased after 4 cycles of nivolumab treatment. Because the biliary enzyme levels did not decrease after ursodeoxycholic acid (UDCA) and antibiotic treatment (AB), liver biopsy was performed. Both prednisolone (PSL) and UDCA immediately improved the biliary enzyme levels. Thus, the patient could receive the alternative chemotherapy. L-OHP: oxaliplatin, Rmab: ramucirumab, nab-PTX: nab- paclitaxel

phils suggested DILI with allergic reaction. The oral administration of prednisolone $(0.5 \mathrm{mg} / \mathrm{kg} / \mathrm{day})$ immediately reduced the levels of serum ALP and $\gamma \mathrm{GTP}$, after which the patient could receive the 5 th and 6 th line chemotherapies. The dose of prednisolone was tapered, and was stopped 4 months later without an increase in the patient's biliary enzyme levels (Fig. 2). As shown in Fig. 2, two months after 3 cycles of nivolumab treatment, the patient's serum carcinoembryonic antigen (CEA) level showed a slight decrease (from $14.7 \mathrm{ng} / \mathrm{mL}$ to $13.7 \mathrm{ng} / \mathrm{mL}$ ). On the other hand, at 2 months after the discontinuation of nivolumab due to the drug-related cholangitis, the patient's CEA level showed a marked increase to $59.6 \mathrm{ng} / \mathrm{mL}$.

\section{Discussion}

In a phase I study of 296 patients with advanced solid tumors, including melanoma, NSCLC, RCC, prostate cancer, and colorectal cancer, increased ALT and ALP levels were noted in $4 \%$ and $1 \%$ of patients, respectively (2). The Checkmate 057 phase III study, which included 292 NSCLC patients revealed that the serum levels of ALT, ALP, and $\gamma$ GTP increased by $3 \%, 1 \%$, and $1 \%$, respectively (18). These data suggest that immune checkpoint inhibitor-related liver injury usually appears as a hepatitis pattern and that the cholangitis pattern is a rare irAE. With regard to cholangitis, only seven cases of nivolumab-related cholangitis in NSCLC and melanoma patients have been reported (Ta- ble 2) (13-17). In addition, nivolumab-induced cholangitis was only reported in 10 of $18,562(0.05 \%)$ patients with metastatic melanoma, NSCLC, RCC, squamous cell carcinoma of the head and neck, or Hodgkin's lymphoma, according to the post-marketing surveillance of the Ministry of Health, Labor and Welfare in Japan from 2014 to 2017 (16).

A previous report that analyzed 2 patients treated with prednisolone suggested that nivolumab-related cholangitis showed a moderate to poor response to steroids therapy (14). As Table 2 indicates, seven cases-including our own-were treated with steroids. With the exception of our case, all cases showed a moderate to poor response to steroid treatment, suggesting that nivolumab-related cholangitis was resistant to steroid treatment. Kawakami et al. reported that the early use of a sufficient quantity of immunosuppressive agents may be effective in terms of clinical improvement (14). In case 6, after increasing the dose of prednisolone from $1 \mathrm{mg} / \mathrm{kg}$ to $2 \mathrm{mg} / \mathrm{kg}$, the patient's biliary enzyme levels gradually improved. If irAEs are refractory to steroid therapy, other immunomodulatory medications such as infliximab, mycophenolate mofetil, tacrolimus, and cyclosporine may be used (12); however, there are no reports regarding hepatitis or cholangitis treated with other immunomodulatory medications, with the exception of a patient who received antithymocyte globulin (19).

Although the initiation of steroid therapy $(1-2 \mathrm{mg} / \mathrm{kg})$ is recommended for patients with immune-related hepatitis (12), the appropriate dose is for patients with immune- 
Table 1. Laboratory Data.

\begin{tabular}{|c|c|c|c|c|c|}
\hline WBC & $7,190 / \mu \mathrm{L}$ & ALP & $2,427 \mathrm{mg} / \mathrm{dL}$ & ANA & $<40$ \\
\hline Neut & $65.5 \%$ & LDH & $198 \mathrm{mg} / \mathrm{dL}$ & AMA & $(-)$ \\
\hline Lymo & $19.2 \%$ & $\gamma$ GTP & $252 \mathrm{U} / \mathrm{L}$ & AMA-M2 & $0.05 \mathrm{U} / \mathrm{mL}$ \\
\hline Mono & $7.9 \%$ & $\mathrm{ChE}$ & $207 \mathrm{U} / \mathrm{L}$ & ASMA & $(-)$ \\
\hline Eos & $6.4 \%$ & BUN & $14.3 \mathrm{mg} / \mathrm{dL}$ & HBs Ag & $<0.01 \mathrm{IU} / \mathrm{mL}$ \\
\hline Baso & $1.0 \%$ & Cre & $0.77 \mathrm{mg} / \mathrm{dL}$ & $\mathrm{HBc} \mathrm{Ab}$ & $0.09 \mathrm{~S} / \mathrm{CO}$ \\
\hline $\mathrm{RBC}$ & $3.89 \times 10^{6} / \mu \mathrm{L}$ & $\mathrm{Na}$ & $140 \mathrm{mEq} / \mathrm{L}$ & HBs $\mathrm{Ab}$ & $0.22 \mathrm{mIU} / \mathrm{mL}$ \\
\hline $\mathrm{Hb}$ & $11.2 \mathrm{~g} / \mathrm{dL}$ & K & $4.0 \mathrm{mEq} / \mathrm{L}$ & $\mathrm{HCV} \mathrm{Ab}$ & $0.05 \mathrm{~S} / \mathrm{CO}$ \\
\hline PLT & $24.6 \times 10^{6} / \mu \mathrm{L}$ & $\mathrm{Cl}$ & $102 \mathrm{mEq} / \mathrm{L}$ & HAV-IgM & $0.26 \mathrm{~S} / \mathrm{CO}$ \\
\hline T.P. & $6.9 \mathrm{~g} / \mathrm{dL}$ & $\operatorname{IgG}$ & $1,296.2 \mathrm{mg} / \mathrm{dL}$ & HEV-IgA & $(-)$ \\
\hline Alb & $3.5 \mathrm{~g} / \mathrm{dL}$ & $\operatorname{IgG} 4$ & $41.0 \mathrm{mg} / \mathrm{dL}$ & CMV-IgG & $\times 47.9$ \\
\hline T. Bil & $0.8 \mathrm{mg} / \mathrm{dL}$ & $\operatorname{Ig} \mathrm{A}$ & $474.4 \mathrm{mg} / \mathrm{dL}$ & CMV-IgM & $<0.08$ \\
\hline D. Bil & $0.2 \mathrm{mg} / \mathrm{dL}$ & $\operatorname{IgM}$ & $57.3 \mathrm{mg} / \mathrm{dL}$ & EBV-VCA IgG & $\times 320$ \\
\hline AST & $69 \mathrm{U} / \mathrm{L}$ & & & EBV-VCA IgM & $<10$ \\
\hline ALT & $68 \mathrm{U} / \mathrm{L}$ & & & EBV-EBNA & $\times 40$ \\
\hline
\end{tabular}

ANA: anti-nuclear antibody, AMA: anti-mitochondrial antibody, ASMA: anti-smooth muscle antibody, HBs Ag: hepatitis B surface antigen, HBc Ab: hepatitis B core antibody, HBs Ab: hepatitis B surface antibody, HCV: hepatitis C virus, HAV: hepatitis A virus, HEV: hepatitis E virus, CMV: cytomegalovirus, EBV: Epstein-Barr virus, VCA: virus capsid antigen, EBNA: EBV nuclear antigen, S/CO: sample cut off

Table 2. Clinical and Pathological Features of Nivolumab-related Cholangitis.

\begin{tabular}{|c|c|c|c|c|c|c|c|c|}
\hline Case & Sex & Age & $\begin{array}{c}\text { Primary } \\
\text { cancer type }\end{array}$ & Portal tract inflammation & $\begin{array}{l}\text { Cycle of } \\
\text { onset }\end{array}$ & Treatment & $\begin{array}{l}\text { Steroid } \\
\text { response }\end{array}$ & $\begin{array}{c}\text { Next } \\
\text { chemotherapy }\end{array}$ \\
\hline $1^{(13)}$ & M & 79 & NSCLC & $\begin{array}{c}\text { CD3+ T lymphocytes } \\
\text { with prevalent CD8+ cells }\end{array}$ & 4 & $\begin{array}{c}\text { Methylprednisolone } \\
(1 \mathrm{mg} / \mathrm{kg}) \\
\text { UDCA }\end{array}$ & Moderate & Impossible \\
\hline $2^{(14)}$ & M & 64 & NSCLC & $\begin{array}{l}\text { CD8+ and CD4+ } \\
\text { T lymphocytes }\end{array}$ & 9 & Prednisolone $(0.5 \mathrm{mg} / \mathrm{kg})$ & Poor & NA \\
\hline $3^{(14)}$ & $\mathrm{F}$ & 73 & NSCLC & NA & 6 & Prednisolone $(0.5 \mathrm{mg} / \mathrm{kg})$ & Moderate & NA \\
\hline $4^{(14)}$ & $\mathrm{F}$ & 82 & NSCLC & $\begin{array}{l}\text { CD8+ and CD4+ } \\
\text { T lymphocytes }\end{array}$ & 12 & NA & NA & NA \\
\hline $5^{(15)}$ & $\mathrm{F}$ & 59 & Melanoma & NA & 3 & $\begin{array}{l}\text { Prednisolone }(1 \mathrm{mg} / \mathrm{kg}) \\
\text { Additional UDCA }\end{array}$ & Poor Good & Possible \\
\hline $6^{(16)}$ & M & 63 & NSCLC & NA & 5 & $\begin{array}{l}\text { Prednisolone }(1 \mathrm{mg} / \mathrm{kg}) \\
\text { Prednisolone }(2 \mathrm{mg} / \mathrm{kg})\end{array}$ & Poor Good & Possible \\
\hline $7^{(17)}$ & M & 69 & NSCLC & NA & 3 & Prednisolone (60 mg/day) & Poor & Impossible \\
\hline Our Case & M & 79 & GC & $\begin{array}{l}\text { CD8+ and CD4+ } \\
\text { T lymphocytes } \\
\text { Eosinophils }\end{array}$ & 4 & $\begin{array}{c}\text { Prednisolone }(0.5 \mathrm{mg} / \mathrm{kg}) \\
\text { UDCA }\end{array}$ & Good & Possible \\
\hline
\end{tabular}

NSCLC: non-small cell lung cancer, GC: gastric cancer, UDCA: ursodeoxycholic acid, NA: not available

related cholangitis is unclear. In addition, our patient was suffered from impaired glucose tolerance (fasting blood glucose level: $114-115 \mathrm{mg} / \mathrm{dL}$ and casual blood glucose level: $189-227 \mathrm{mg} / \mathrm{dL})$; thus, a low dose of prednisolone $(0.5 \mathrm{mg} /$ $\mathrm{kg}$ ) was administered. After the administration of a low dose of prednisolone, the patient's biliary enzyme levels immediately decreased. Histopathological findings of CD4+ and $\mathrm{CD} 8+\mathrm{T}$ lymphocyte infiltration into the portal tract were consistent with a pathological feature of irAE, as suggested by a previous report (14). In contrast, eosinophilic infiltration is a feature of an immunoallergic reaction, which is generally associated with a better prognosis in patients with DILI (20). Indeed, a blood examination revealed eosinophilia $(\geq 6 \%$ ), which is one of the diagnostic criteria for DILI with allergic reaction in Japan (21). These histological findings indicated that the present case had the features of both irAE and DILI with allergic reaction. Although the role of eosinophilia in the peripheral blood and liver is unclear, one possible reason why our patient immediately improved after treatment with a low-dose prednisolone is because the patient showed histopathological features of both irAE and DILI with allergic reaction. In contrast, the serum ALP levels gradually improved with both methylprednisolone and UDCA treatment in case 1 . In addition, the first prednisolone treatment was not effective in case 5; however, the patient's biliary enzyme levels gradually improved after additional UDCA treatment. These findings suggest that the administration of both steroids and UDCA may improve nivolumab-related cholangitis.

The marked infiltration of both CD4+ and CD8+ T lym- 
phocytes in this case was a salient histopathological feature, which is consistent with previous reports of nivolumabrelated cholangitis with an irAE (13-17). However, previous reports have demonstrated that drug-induced cholangitis or eosinophilic cholangitis is associated with periportal mixed inflammatory infiltration including lymphocyte infiltration (22-24). Although the immunophenotypes of these lymphocytes have not been shown in these studies, CD4+ and CD8+ T lymphocytes could be recruited in such conditions. Thus, it should be noted that cholangitis due to irAE cannot be clearly distinguished from allergic cholangitis by pathological features alone.

Recently, a correlation between irAEs and anti-tumor effects was reported in patients with lung cancer and melanoma (25-27). In the present case, the patient's CEA level did not increase during nivolumab treatment while the patient's CEA level increased after the discontinuation of the drug. These findings might suggest the persistent efficacy of nivolumab treatment, thereby supporting the fact that irAE patients demonstrated a favorable efficacy for nivolumab treatment.

In conclusion, we reported a case of nivolumab-related cholangitis in a patient with recurrent gastric cancer who showed an immediate response to prednisolone therapy and who could receive alternative chemotherapy. Because it is important to evaluate and treat nivolumab-related cholangitis before resuming subsequent chemotherapy, prednisolone should be administered if a blood examination reveals eosinophilia and if the histopathological analysis of a liver biopsy specimen reveals eosinophils and CD4+ or CD8+ T lymphocyte infiltration.

The authors state that they have no Conflict of Interest (COI).

\section{References}

1. Brahmer JR, Drake CG, Wollner I, et al. Phase I study of singleagent anti-programmed death-1 (MDX-1106) in refractory solid tumors: safety, clinical activity, pharmacodynamics, and immunologic correlates. J Clin Oncol 28: 3167-3175, 2010.

2. Topalian SL, Hodi FS, Brahmer JR, et al. Safety, activity, and immune correlates of anti-PD-1 antibody in cancer. N Engl J Med 366: 2443-2454, 2012.

3. Topalian SL, Sznol M, McDermott DF, et al. Survival, durable tumor remission, and long-term safety in patients with advanced melanoma receiving nivolumab. J Clin Oncol 32: 1020-1030, 2014.

4. Rizvi NA, Mazières J, Planchard D, et al. Activity and safety of nivolumab, an anti-PD-1 immune checkpoint inhibitor, for patients with advanced, refractory squamous non-small-cell lung cancer (CheckMate 063): a phase 2, single-arm trial. Lancet Oncol 16: 257-265, 2015.

5. Cella D, Grünwald V, Nathan P, et al. Quality of life in patients with advanced renal cell carcinoma given nivolumab versus everolimus in CheckMate 025: a randomised, open-label, phase 3 trial. Lancet Oncol 17: 994-1003, 2016.

6. Ferris RL, Blumenschein G Jr, Fayette J, et al. Nivolumab for recurrent squamous-cell carcinoma of the head and neck. N Engl J Med 375: 1856-1867, 2016.
7. Ansell SM, Lesokhin AM, Borrello I, et al. PD-1 blockade with nivolumab in relapsed or refractory Hodgkin's lymphoma. N Engl J Med 372: 311-319, 2015.

8. Kang YK, Boku N, Satoh T, et al. Nivolumab in patients with advanced gastric or gastro-oesophageal junction cancer refractory to, or intolerant of, at least two previous chemotherapy regimens (ONO-4538-12, ATTRACTION-2): a randomised, double-blind, placebo-controlled, phase 3 trial. Lancet 390: 2461-2471, 2017.

9. Friedman CF, Proverbs-Singh TA, Postow MA. Treatment of the immune-related adverse effects of immune checkpoint inhibitors: a review. JAMA Oncol 2: 1346-1353, 2016.

10. Nishino M, Giobbie-Hurder A, Hatabu H, Ramaiya NH, Hodi FS. Incidence of programmed cell death 1 inhibitor-related pneumonitis in patients with advanced cancer: a systematic review and meta-analysis. JAMA Oncol 2: 1607-1616, 2016.

11. Godwin JL, Jaggi S, Sirisena I, et al. Nivolumab-induced autoimmune diabetes mellitus presenting as diabetic ketoacidosis in a patient with metastatic lung cancer. J Immunother Cancer 5: 40, 2017.

12. Spain L, Diem S, Larkin J. Management of toxicities of immune checkpoint inhibitors. Cancer Treat Rev 44: 51-60, 2016.

13. Gelsomino F, Vitale G, D'Errico A, Bertuzzi C, Andreone P, Ardizzoni A. Nivolumab-induced cholangitic liver disease: a novel form of serious liver injury. Ann Oncol 28: 671-672, 2017.

14. Kawakami H, Tanizaki J, Tanaka K, et al. Imaging and clinicopathological features of nivolumab-related cholangitis in patients with non-small cell lung cancer. Invest New Drugs 35: 529-536, 2017.

15. Doherty GJ, Duckworth AM, Davies SE, et al. Severe steroidresistant anti-PD1 T-cell checkpoint inhibitor-induced hepatotoxicity driven by biliary injury. ESMO Open 2: e000268, 2017.

16. Kashima J, Okuma Y, Shimizuguchi R, Chiba K. Bile duct obstruction in a patient treated with nivolumab as second-line chemotherapy for advanced non-small-cell lung cancer: a case report. Cancer Immunol Immunother 67: 61-65, 2018.

17. Kuraoka N, Hara K, Terai S, Yatabe Y, Horio Y. Peroral cholangioscopy of nivolumab-related (induced) ulcerative cholangitis in a patient with non-small cell lung cancer. Endoscopy 50: E259E261, 2018.

18. Borghaei H, Paz-Ares L, Horn L, et al. Nivolumab versus docetaxel in advanced nonsquamous non-small-cell lung cancer. N Engl J Med 373: 1627-1639, 2015.

19. Chmiel KD, Suan D, Liddle C, et al. Resolution of severe ipilimumab-induced hepatitis after antithymocyte globulin therapy. J Clin Oncol 29: e237-e240, 2011.

20. Kleiner DE, Chalasani NP, Lee WM, et al. Hepatic histological findings in suspected drug-induced liver injury: systematic evaluation and clinical associations. Hepatology 59: 661-670, 2014.

21. Takikawa H, Takamori Y, Kumagi T, et al. Assessment of 287 Japanese cases of drug induced liver injury by the diagnostic scale of the International Consensus Meeting. Hepatol Res 27: 192-195, 2003.

22. Visentin M, Lenggenhager D, Gai Z, Kullak-Ublick GA. Druginduced bile duct injury. Biochim Biophys Acta Mol Basis Dis 1864: 1498-1506, 2018.

23. Nashed C, Sakpal SV, Shusharina V, Chamberlain RS. Eosinophilic cholangitis and cholangiopathy: a sheep in wolves clothing. HPB Surg 2010: 906496, 2010.

24. Iwamuro $M$, Yamamoto $K$, Kawamoto $H$, Terada R, Ogawa $T$, Nose S. Eosinophilic cholangitis with initial clinical features indistinguishable from IgG4-related cholangitis. Intern Med 48: 11431147, 2009.

25. Sato K, Akamatsu H, Murakami E, et al. Correlation between immune-related adverse events and efficacy in non-small cell lung cancer treated with nivolumab. Lung Cancer 115: 71-74, 2018.

26. Teraoka S, Fujimoto D, Morimoto T, et al. Early immune-related 
adverse events and association with outcome in advanced nonsmall cell lung cancer patients treated with nivolumab: a prospective cohort study. J Thorac Oncol 12: 1798-1805, 2017.

27. Weber JS, Hodi FS, Wolchok JD, et al. Safety profile of nivolumab monotherapy: a pooled analysis of patients with advanced melanoma. J Clin Oncol 35: 785-792, 2017.
The Internal Medicine is an Open Access journal distributed under the Creative Commons Attribution-NonCommercial-NoDerivatives 4.0 International License. To view the details of this license, please visit (https://creativecommons.org/licenses/ by-nc-nd/4.0/).

(C) 2019 The Japanese Society of Internal Medicine Intern Med 58: 1747-1752, 2019 